\title{
Impact of the Fabrication Parameters on the Performance of Embroidered E-clothes
}

\author{
Eman M. Swielam*1, Samiea M. Eltopshy², Sania K. Sobhy ${ }^{2}$, Z. M. Abdel- \\ megied $^{1}$ and Ahmad M. Labeeb ${ }^{3}$ \\ ${ }^{1}$ Clothing \& Knitting Industrial Research Department, Textile Research Division, \\ National Research Centre (NRC), Giza, 12622, Egypt. \\ ${ }^{2}$ Clothes \& Textile Department, Faculty of Home Economics, Helwan University, Egypt. \\ ${ }^{3}$ Microwave Physics and Dielectrics, Physics Research Division, National Research \\ Centre (NRC), Giza, 12622, Egypt.
}

\begin{abstract}
$\mathbf{T}$
HE research was conducted to apply the embroidering technique of fabricating e-textiles. Two types of conductive threads (A1\& A2) were used. Microstructure properties of conductive yarns were characterized by energy dispersive X-ray (EDX) and scanning electron microscopy (SEM). Embroidery process was done by computerized embroidery machine. The effects of embroidery parameters such as different stitch type, stitch length and number of embroidered conductive threads on embroidered lines resistance were compared. The best result of conductivity and coating uniformity was obtained when using the type (A1) of coated yarn in straight stitch type with 3 lines of thread with $5 \mathrm{~mm}$ stitch length. Due to its low value of resistance (R) $0.83 \Omega$, while the highest value was $10.66 \Omega$ in the type (A2) conductive yarn in zigzag stitch type with 1 line of thread with $7 \mathrm{~mm}$. stitch length. The A1 yarn type embroidered on a prototype T-shirt to be a connector between the temperature sensor and screen. This embedded system based on conductive thread could find possible application in medical applications: continuous and long-term monitoring of patients in a hospital environment.
\end{abstract}

Keywords: Smart Clothes, Conductive Yarn, Embroidery, Wearable technology, EDX, SEM \& E-textile.

\section{Background}

Smart textiles and clothes have attracted the researcher's attention in the last decade for their usages in wearable technologies [1]. Textiles are the most materials that we interact with during our daily life. The implementation of "smart clothes", including wearable electronics, opens doors for the next level of integration as user friendly interfaces and smart power management will allow clothes to offer additional functions such as integrated communications capability or vital functions monitoring [2-4].

Smart clothing integrated with Soft sensors and actuators have been developed for interaction with environment, increase of operator's safety, entertainment and physiological parameters monitoring [5]. Conductive fibres are the key element to build smart fabrics with known electrical properties (resistance, capacitance etc.).
The current conduction in fabrics depends on: conductive material used percentage of conductive fibres, fabric structure and conductive fibre contact surface. Capineri, [6], described the fabrication technologies, which use metal fibres only and a mixture with textile fibres. These yarns are produced using textile production technologies. Advanced processes of metallization of polyamide fibres with silver coating are also developed because polyamide gives the yarn strength and elasticity besides having biocompatibility with human body, while thin compliant silver coating guarantees electrical conductivity. Carbon fibres can also be used to produce smart fabrics, for the fact that carbon is a conductive material.

For textile, sensors are able to measure: mechanical pressure, strain, position (potentiometer) and temperature. For each type of smart textile, resistive device is important the characterization of the performances with laboratory test under electrical, mechanical and temperature conditions.

*Corresponding author e-mail: emanswielam@gmail.com DOI: 10.21608/ejchem.2018.4555.1399

(C)2017 National Information and Documentation Center (NIDOC) 
The conductive layer can be either carbon nanotubes or metal [7]. The options of metal plated conductive threads are wide. The coating material can be chosen from different metals to balance the performance and the cost. Normally, silver, copper and nickel are the options for commercialized products that can provide a balance between electrical conductivity, mechanical strength and flexibility. Generally, polymer based conductive threads are easy to embroider due to the physical similarity as well as traditional embroidery threads [8].

There are two fundamental ways to produce a conductive fabric component. In the first, a nonconductive fabric may be plated with a conductor. The other approach is using a conductive yarn on a non-conductive substrate [9]. This approach uses knitting, embroidery or weaving as the most common fabrication techniques [10]. Electrically conductive fibres are key component of the smart and interactive textiles that will be used in the future. Thus, they have a wide feature as power and signal transmitters in many prospective applications such as strain sensors and electrothermal sensors.

The embroidery allows control and integration of yarn with different electrical properties, such as different resistances as well as offering many advantages over knitting or weaving. Therefore, Conductive thread and yarn embroidery can be accomplished on single or multiple layers of fabric. Moreover, it can be applied to various types of textile and apparel products in one-step such as Antenna and sensors [11,12]. Zhang et al.[13] showed that the embroidered fabric based antenna systems including transmission lines and low-profile detachable connectors have been applied to produce smart clothing. So, embroidery was chosen as a production technique.

The aim of this research was studying the impact of the fabrication parameters such as using different types of stitches and conductive yarns on the performance of embroidered E-textiles, which could be applied in wearable technology in the military and medical fields.

\section{Materials and Methods}

Conductive Threads characterization

Two types of multifilament conductive threads based on the composition of the filaments have been used:

1. (Lebrator 40 KururayVectran ${ }^{\circledR}$ Outer Metallization Layer silver as material (A1).

2. Silver Sheildx ${ }^{\circledR} 92$ conductive yarn as Material (A2) from Syscom Advanced Materials - U.S.

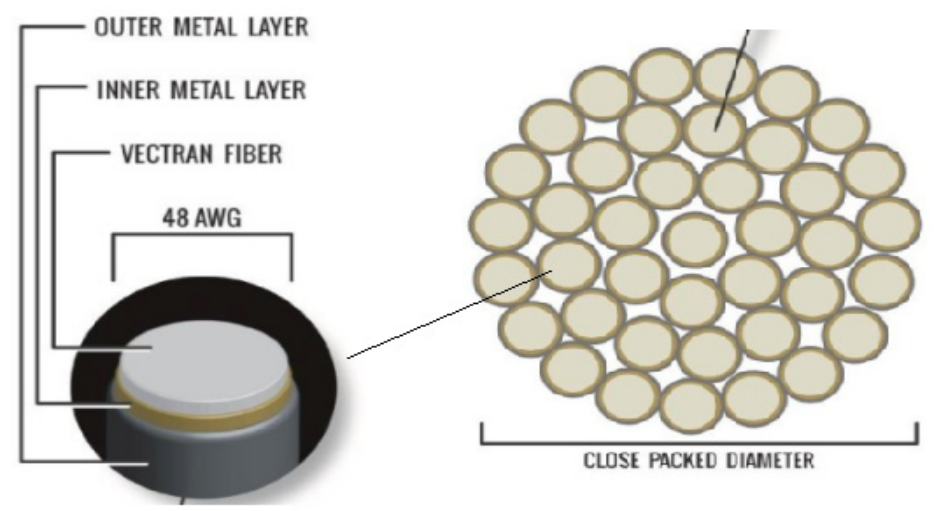

Fig. 1. Across-section of Silver Conductive yarns Lebrator 40 KururayVectran ${ }^{\circledR}$

Scanning electron microscopy SEM and energy dispersive X-ray EDX characterization.

The instrument Quanta standard Environmental Scanning electron microscope SEM with Energy Dispersive X-ray detector (EDX) at $20 \mathrm{kV}$ was employed to observe the morphology of the samples and perform EDX analyses. Scanning electron microscopy (SEM) analyses were performed

Egypt.J.Chem. 62, No. 1 (2019) using an acceleration voltage of $20 \mathrm{kV}$. EDX measurements were done in companion of imaging by SEM between 5 and $20 \mathrm{kV}$. The preparations of samples for SEM measurements were coated with golden layer Au using a Sputter Coater Bal-Tec SCD 005. The EDX measurements were carried out for sample A1\& A2. The average fibre diameter was obtained from the SEM images. 
Tensile strength testing of conductive yarns

The tenacity and strain properties of conductive yarns were tested using an Instron Tensile Tester (USA) according to ASTM D2256.

\section{Embroidering Conductive Threads}

Computerized Embroidery Machine and Stitch Patterns.

The design was relied on:

- Two types of conductive yarns, which embroidered in straight and zigzag stitch types.

- The parameters were used length of stitch with $(3,5 \& 7 \mathrm{~mm})$ and 1,2 and 3 lines of threads.

The embroidering process was fabricated using a computerized embroidery machine (MEYAG model 912) as shown in Fig. 2 A. The specifications of embroidering geometries were designed using Wilcom Embroidery Studio, ES 65 Designer software on a computer. The defining characteristics including dimensions, arrangement, stitch type and stitch direction of each embroidered objects can be controlled with software for the embroidery machine as shown in Fig. 2C.

Studio, ES 65 Designer software and film of embroidery design containing the straight stitch type with different spacing and length of stitch (on the right ) and the zigzag stitch type with different spacing and length of stitch (on the left).

Different patterns of embroidered stitches. Considering the current flowing path, Satin stitch and Running stitch are used in this study. Satin stitch is the zigzag pattern that perpendicular to the designed direction. Usually it creates a bold line. Running stitch is a single line of stitch that follows the designed direction. Clearly the running stitch creates the thinnest line compared with other stitches and uses the least length of thread for the same distance. Comparison between these two stitches will be presented [13].

\section{Model of Embroidered Stitches}

The stitch formation predominantly utilized in this study is the 'lock stitch' which is the most commonly used in embroidery. The lock stitch as a standard stitch, both for its simplicity and the fact that it tends to produce fabric conductors with lower resistance than other stitch types considered [8].

The lock stitch is created with a top thread and a lopper thread. The conductive thread on the top of a base fabric embroiders the conductive layer. A nonconductive thread (usually cotton or polyester yarn) is used to lock the conductive thread via the holes in the fabric. The depths of the holes are equal to the thickness of the fabric. A
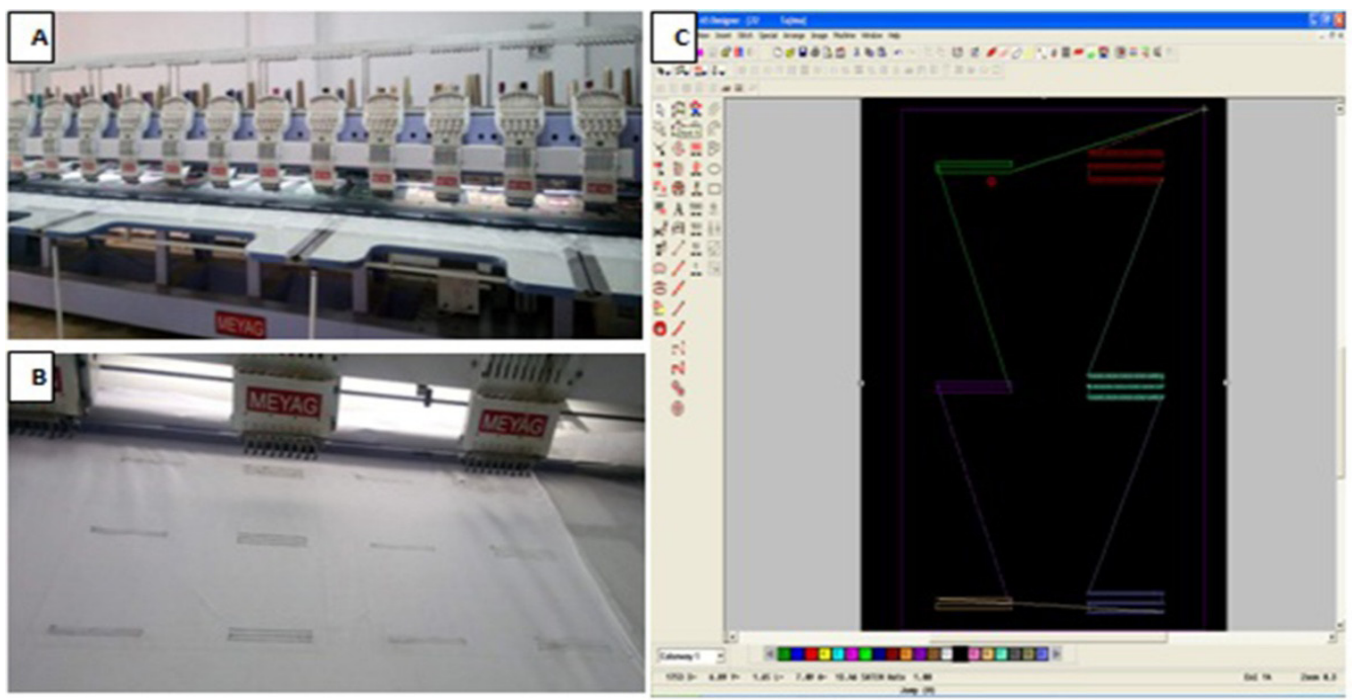

Fig. 2. Embroidery process using computerized embroidery machine.

A; The computerized embroidery machine (MEYAG model 912)

B; the embroidered samples.

C; the window of the Wilcom Embroidery Studio, ES 65 Designer software and film of embroidery design containing the straight stitch type with different spacing and length of stitch (on the right) and the zigzag stitch type with different spacing and length of stitch (on the left). 


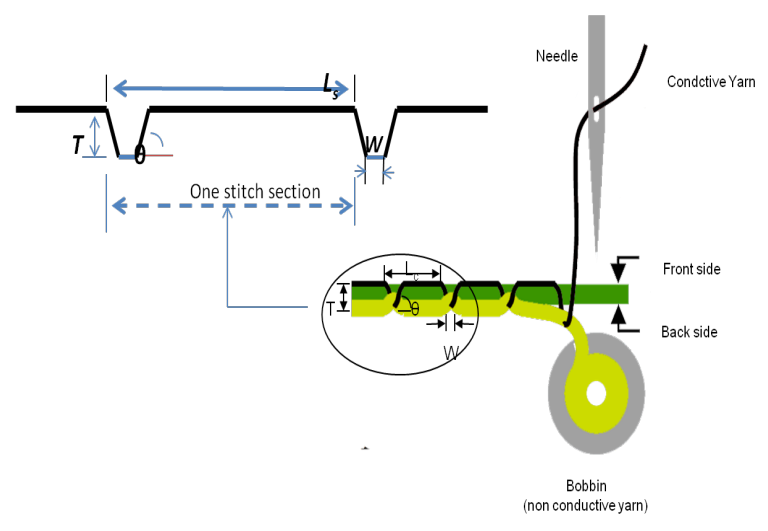

Fig. 3. Model of embroidered conductive thread length using lock stitches.

model was built to estimate the total length of the used thread (see Fig. 3). Taking running stitch as an example, the diagram illustrates the conductive embroidery thread only.

Electrical properties of embroidered conductive threads

Digital millimetre (Metex - M3800) was used. Samples were air-conditioned and measurement was carried out at $40 \% \mathrm{RH}, 22^{\circ} \mathrm{C}$. The resistance of the total length of the used thread based on type, length and depth of stitch was calculated according to [8].

\section{Experimental Design}

TABLE 1. Tenacity of conductive yarns (A1\&A2).

\section{Data Analysis}

The data were subjected to ANOVA and were evaluated by MSTATC program. The differences between means were compared using LSD test at $5 \%$ level of significance.

\section{Results and Discussion}

Tenacity Strength of conductive yarns

The tenacity strength of the first type (A1) was $0.060 \pm 006 \mathrm{~g} / \mathrm{den}$ while the other type (A2) was $0.012 \pm 000$ as shown in Table 1 . The thickness of yarn could be contributed to the tenacity strength.

\begin{tabular}{|c|c|c|c|c|}
\hline & $\begin{array}{c}\text { Load maximum } \\
\left(\mathrm{Kgf} / \mathrm{m}^{2}\right)\end{array}$ & $\begin{array}{c}\text { Tenacity at } \\
\text { maximum (g/den) }\end{array}$ & $\begin{array}{l}\text { Strain at Maximum } \\
(\mathrm{mm} / \mathrm{mm})\end{array}$ & $\begin{array}{c}\text { Strain at Maximum } \\
(\%)\end{array}$ \\
\hline Yarn A1 & $12.225 \pm 1.144$ & $0.060 \pm 0.006$ & $0.039 \pm 0.006$ & $3.903 \pm 0.617$ \\
\hline Yarn A2 & $10.032 \pm 0.051$ & $0.012 \pm 000$ & $0.008 \pm 0.008$ & $18.881 \pm 0.790$ \\
\hline
\end{tabular}

*Values are mean \pm S.D.

\section{Scanning electron microscopy}

The SEM graphs in Fig.4 A \& B show diameter of A1, with outer metallization layers Silver ranged from $23.58-28.62 \mu \mathrm{m}$. the diameter was measured via SEM for A2, to be 27.48-29.68 $\mu \mathrm{m}$. Obviously, there is imperfection in coating layer thickness and at some parts the coated layer is broken of filaments more than another type. The presence of $\mathrm{Ag}$ and/or $\mathrm{Ni}$ in the different types of yarns was investigated by Energy Dispersive X-ray scattering EDX analysis as shown in Fig.4 A\&B. The Ag \& Ni content as weight percentage was $38.54 \& 29.15$ in Labrador 40 yarn with Egypt.J.Chem. 62, No. 1 (2019) outer metallization layers silver, while the weight percentage of Ag was $34.80 \%$ of silver A2 yarn.

\section{Electrical properties of conductive Yarns}

There are two types of stitches as zigzag stitch and straight stitch with different lengths 3,5 , and $7 \mathrm{~mm}$. The lowest value of resistance $(\mathrm{R}=0.83$ $\Omega$ ) was found in A1 sample with Silver coating in straight stitch type with 3 lines of thread in the $5 \mathrm{~mm}$ stitch length. Whereas, the highest value $(\mathrm{R}=10.66 \Omega)$ was detected to $\mathrm{A} 2$ conductive yarn in zigzag stitch type with 1 line of thread in the 7 $\mathrm{mm}$ stitch length. 


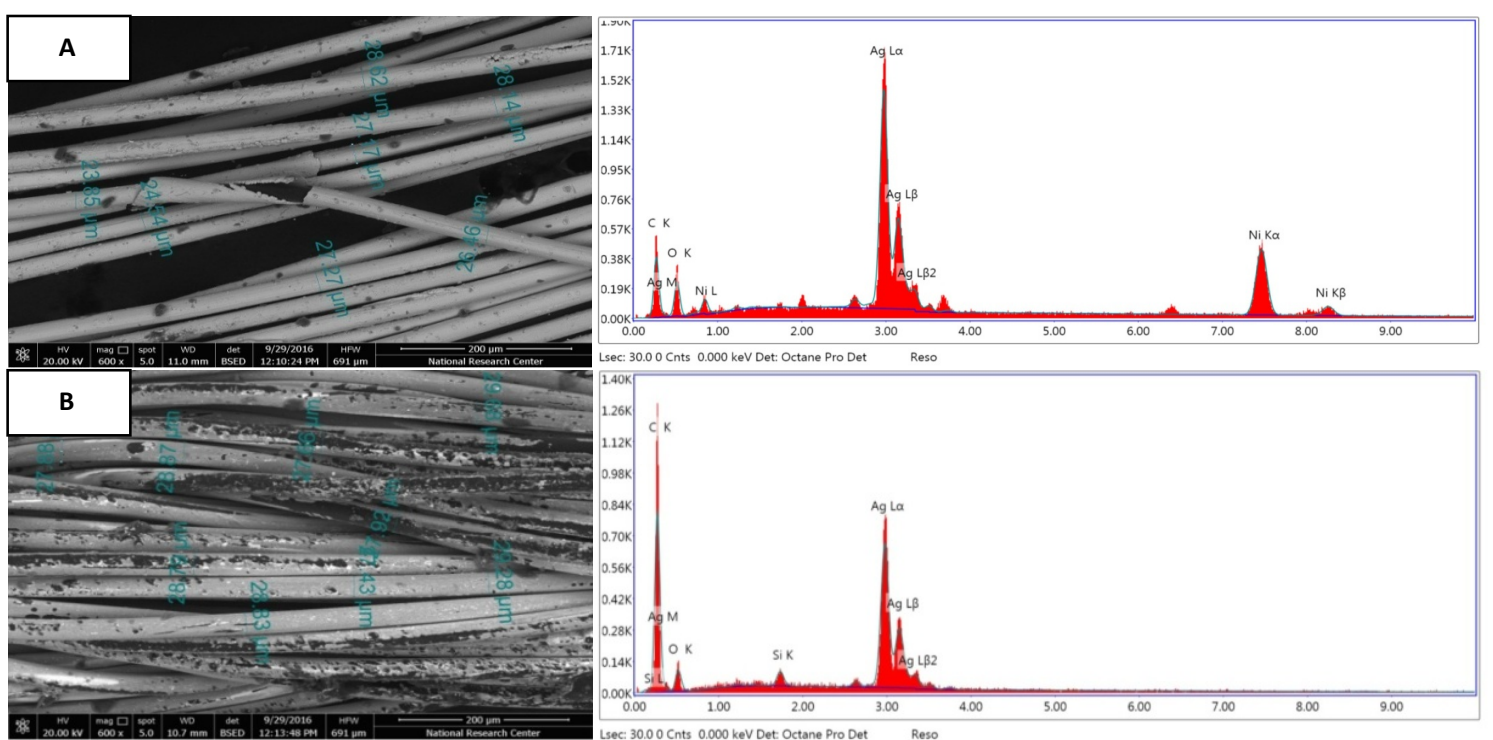

Fig. 4. SEM Micrographs and EDX spectrum of A1 (A) and A2 (B).

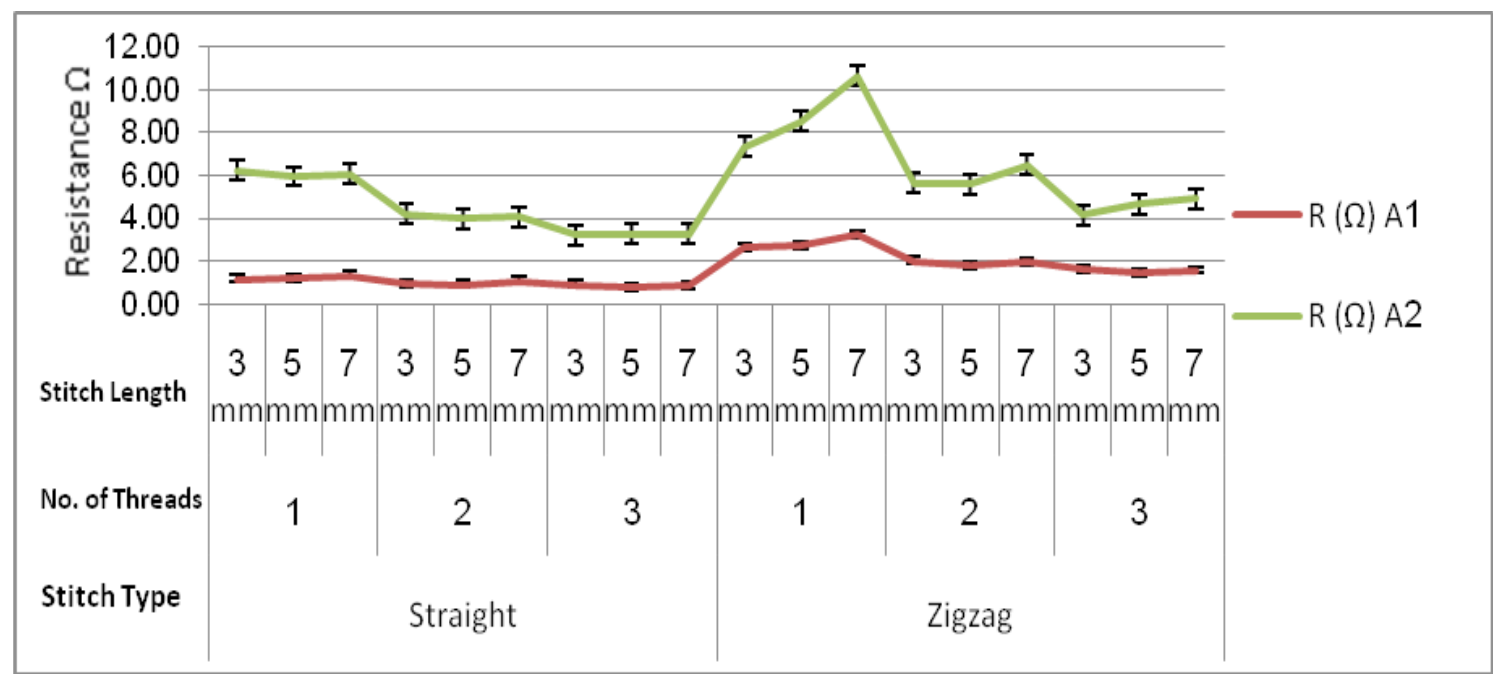

Fig. 5. Effect of Yarn Type, Stitch Type, Thread No.and stitch Length (mm) on R $(\Omega)$.

The mean value of $\mathrm{R}(\Omega)$ for Labrador 40 coated with Silver layers was $1.591 \Omega$. Whereas, the Silver Sheildx 92 conductive yarns was $5.461 \Omega$ as shown in Fig. 6. The type of stitch affected on mean value of resistance $R(\Omega)$ as $2.31 \Omega$ for straight stitches while was $3.8 \Omega$ for Zigzag stitches as shown in Fig 7.

Moreover, the number of stitches lines of thread influences on resistance mean values as $4.091,2.907$ and $2.278 \Omega$ for the 1,2 and 3 lines of threads respectively. Means of $\mathrm{R}(\Omega)$ were $2.848,2.956$ and $3.472 \Omega$ of the length of stitches 3, 5 and $7 \mathrm{~mm}$ significant respectively as shown in Fig. 8\&9. Zhang et al. [13] found that resistivity for the silver Coated material $(\Omega \bullet \mathrm{m})$ of Liberator Silver $40,1.59 \times 10^{-8}(\Omega \bullet \mathrm{m})$ and DC resistance of $100 \mathrm{~mm}$ single thread $(\Omega) 4.3(\Omega)$ and resistivity for the Nickel Coated material $(\Omega \cdot \mathrm{m})$ of Amber strand Nickel 166, 6.99 $\times 10^{-8}$ $(\Omega \bullet \mathrm{m})$ and DC resistance of $100 \mathrm{~mm}$ single thread $(\Omega) 0.3(\Omega)$. Longer stitch lengths can also reduce the total thread usage but the threads are loosed and wrinkled easily. The optimum base material and stitch length can provide the balance between the quality of embroidered pattern and the total required length of the conductive thread. A low resistivity indicates a wire that readily allows the movement of electrical charge. Silver is the best conductors for electric current [14,15].

Egypt.J.Chem. 62, No. 1 (2019) 


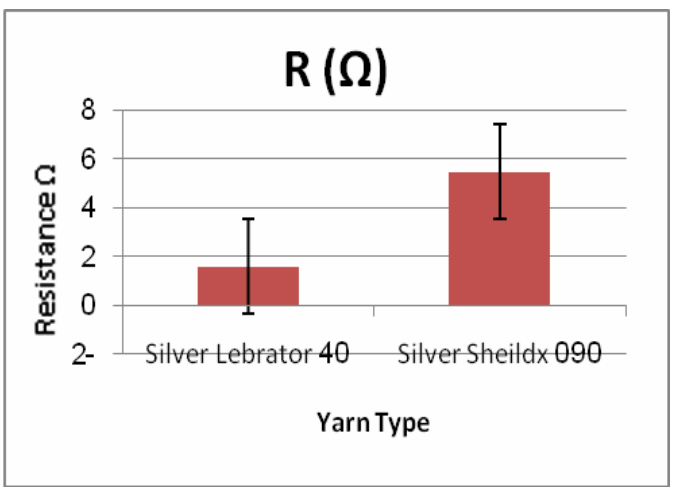

Fig. 6. Means of $R(\Omega)$ of the different types of yarns.

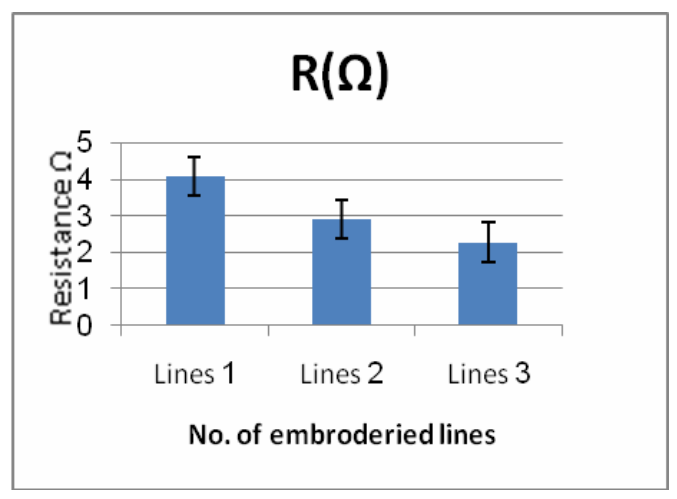

Fig. 8. Means of $R(\Omega)$ of the Number of lines.

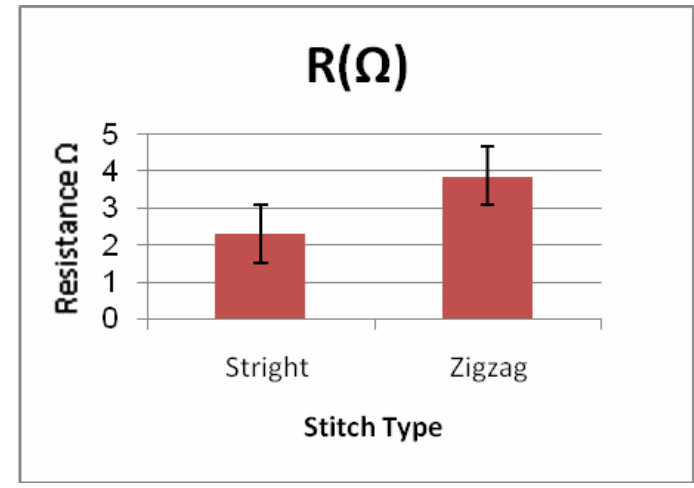

Fig. 7. Means of $R(\Omega)$ of the different types of stitches.

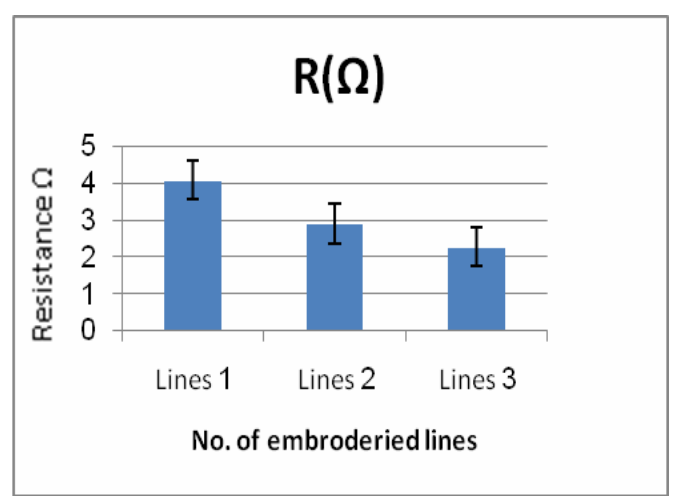

Fig. 9. Means of $R(\Omega)$ of the stitches length.

TABLE 2. Model of Embroidering and Stitch Patterns.

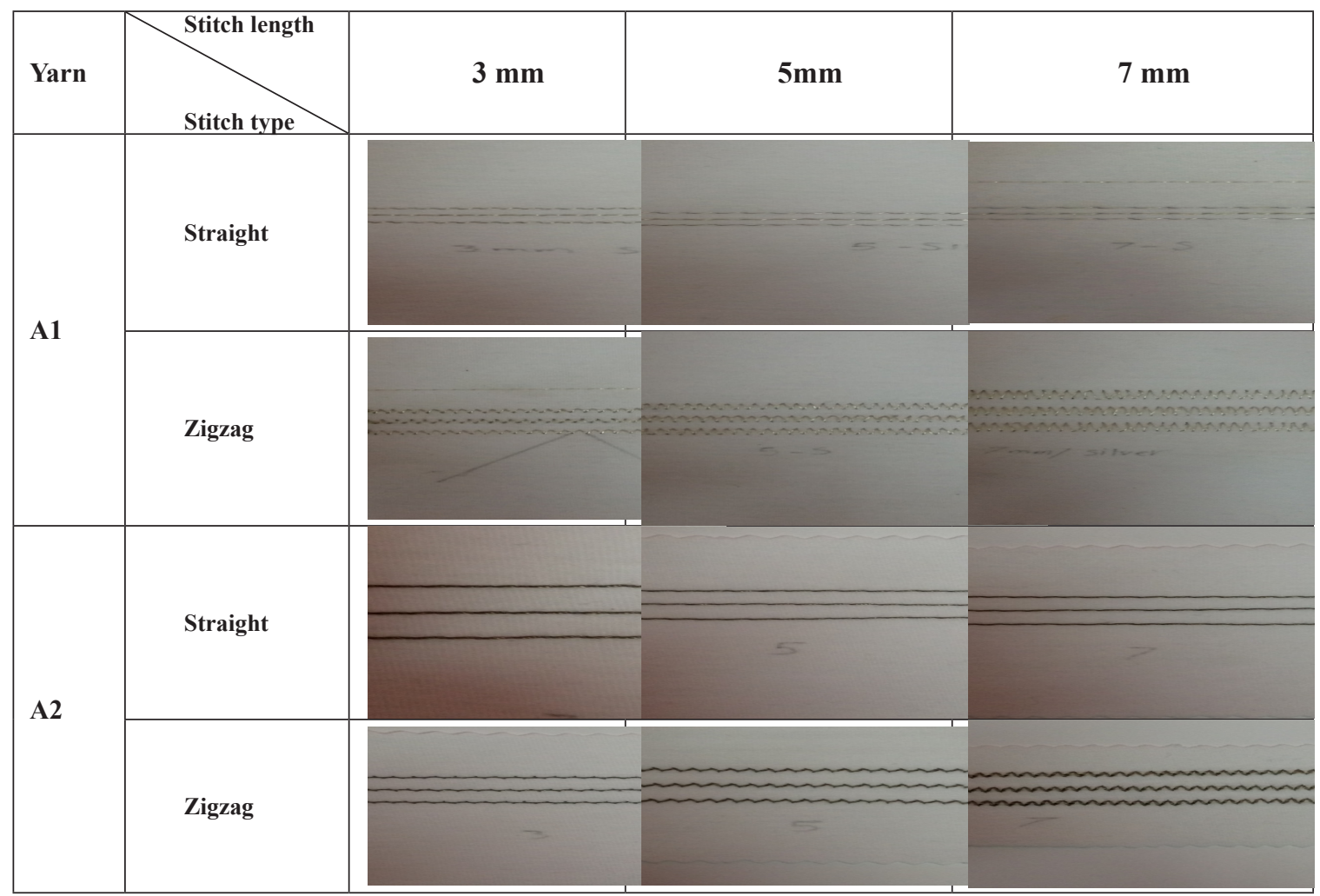

Egypt.J.Chem. 62, No. 1 (2019) 
Based on the obtained results, the A1 yarn type was embroidered on a prototype T-shirt to be a connector between the temperature sensor and screen. This embedded system based on conductive thread could find possible application in medical applications as shown in Fig 10.

\section{Conclusion}

Two types of conductive threads (A1 \& A2) are used, which embroidered in straight and zigzag stitch types with different length of stitch and 1, 2 and 3 lines of threads. The obtained resulted,

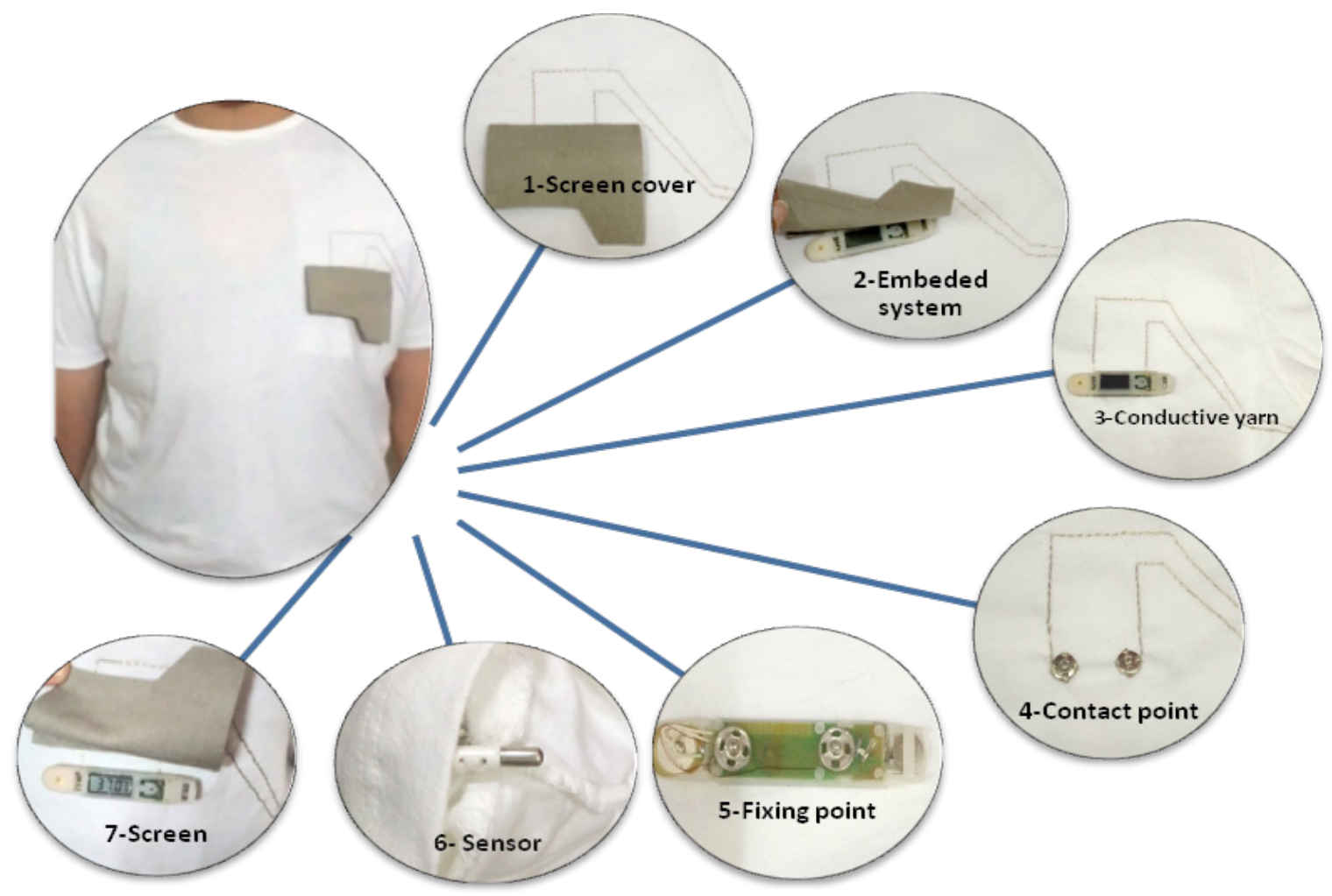

Fig. 10. Mode Proto type of the Smart T-shirt for monitoring of the human body temperature

Components of embedded system for human body temperaturemonitoring; 1-Screen cover, 2-Embeded system, 3-Conductive yarn, 4-Contact point, 4-Contact point, 6- Sensor, 7-Screen

showed that the lowest value of resistance $(R)$ was $0.83 \Omega$ of A2 in straight stitch type with 3 lines of thread with $5 \mathrm{~mm}$ stitch length, the mean of resistance increased with the increasing of stitch length and decreased with the increasing the line of thread. Therefore, the suitable conductive yarn is the Labrador 40 with outer metallization layers Silver A1. The A1 yarn type could be embroidered on a prototype T-shirt to be a connector between the temperature sensor and screen. This embedded system based on conductive thread could find possible application in medical applications: continuous and long-term monitoring of patients in a hospital environment Generally, by integrating sensors, the data processing, storage and transmission circuitry in clothing, the patient's comfort, mobility and privacy would be increased. Moreover, as textile materials are used for the sensors, antenna and interconnections, the integration is increased, resulting in even more patient-friendliness and the wash ability (and thus reuse) of the suit is obtained.

\section{$\underline{\text { References }}$}

1. Marculescu, D., Marculescu, R., Zamora, N. H., Stanley-marbell P., Khosla P. K., Park S., Jayaraman S., Jung S., Lauterbach, C., Werner, W., Kirstein T., Cottet, D., Grzyb, J., Tröster, G., Jones, M., Martin, T. and Zahi Nakad, Electronic Textiles: A Platform for Pervasive Computing. Proceedings of the IEEE, 91, 1995-2018 (2003).

2. Catrysse, M., Puers, R., Hertleer, C., Van Langenhove, L., Van Egmond, H., \& Matthys, D., Towards the integration of textile sensors in a wireless monitoring suit. Sensors and Actuators,

Egypt.J.Chem. 62, No. 1 (2019) 
A: Physical, 114(2-3), 302-311 (2004), https://doi. org/10.1016/j.sna.2003.10.071.

3. Silva, M., Catarino, A. Carvalho, H. Rocha, A. Study of vital sign monitoring with textile sensors in swimming pool environment, 1, pp. 4426-4431 (2009).

4. Lacerda Silva, N., Gonçalves, L. M., \& Carvalho, H.. Deposition of conductive materials on textile and polymeric flexible substrates. Journal of Materials Science: Materials in Electronics, 24(2), 635-643 (2013).https://doi.org/10.1007/s10854-012-0781-y.

5. Dalsgaard, C., \& Sterrett, R., Market Opportunities for Smart Textiles 2014 White paper on smart textile garments and devices: a market overview of smart textile wearable technologies. Ohmatex APS, 1-11 (2014). Retrieved from http://www. innovationintextiles.com/uploads/2772/Ohmatex Whitepaper_2014final (2).pdf.

6. Capineri, L., Resistive sensors with smart textiles for wearable technology: from fabrication processes to integration with electronics, Procedia Eng.,.87, 724-727 (2014).

7. Miao, M. Electrical conductivity of pure carbon nanotube yarns. Carbon, 49(12), 3755-3761 (2011).

8. Zhang, S.,.Design Advances of Embroidered Fabric Antennas. Loughborough University (2014).

9. Chauraya, A., Zhang, S., Whittow, W., Acti, T., Seager, R., Dias, T., \& Vardaxoglou, Y. C. Addressing the challenges of fabricating microwave antennas using conductive threads. In: 2012 6th
European Conference on Antennas and Propagation (EUCAP) pp.1365-1367 (2012), IEEE. https://doi. org/10.1109/EuCAP.2012.6205910

10. Seager, R., Zhang, S., Chauraya, A., Whittow, W., Vardaxoglou, Y., Acti, T., \& Dias, T. Effect of the fabrication parameters on the performance of embroidered antennas, 7 (January), 1174-1181 (2013). https://doi.org/10.1049/iet-map.2012.0719

11. Mac, T.; Houis, S.; Gries, T. In Proceeding of the International Conference on Shape Memory and Superelastic Technologies. In: Metal Fibers. Baden-Baden (2004).

12. Stoppa, M. \& Chiolerio, A. Wearable Electronics and Smart Textiles: A Critical Review. Sensors, 14, 11957-11992 (2014). https://doi.org/10.3390/ s140711957

13. Zhang, S., Chauraya, A., Whittow, W., Seager, R., Acti, T., Dias, T., \& Vardaxoglou, Y. Embroidered Wearable Antennas Using Conductive Threads with Different Stitch Spacings, Loughborough Antennas \& Propagation Conference Proceedings 6-9 (2012).

14. Ová, V. Š. ̌̌., \& Grégr, J., Electrical conductivity measurement of fibers and yarns, International Conference- (TEXSCI), Proceedings, 2-9 (2010).

15. Morton, W.E.; J.W.S, H.. Physical Properties of Textile Fibres. London: Woodhead Publishing, (2008).

(Received 24/7/2018;

accepted $11 / 8 / 2018$ ) 


\title{
تأثثير معاملة التصنيع علي أداء الملابس الأكية المطرزة
}

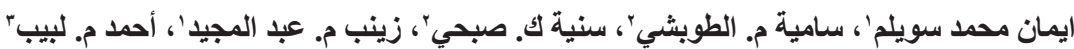

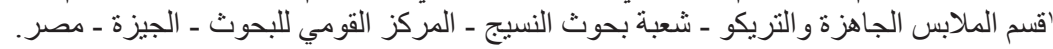

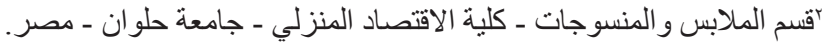
"قفم الموجات الميكرونية ـ شعبة بحوث الفية الفيزياء ـ المركز القومي للبحوث ـ ـ الجيزة ـ مصر.

\begin{abstract}
أجري هذا البحث لار اسة تطبيق تقنية التطريز في صناعة المنسوجات الإلكترونية. حيث تم استخدام نو عين من الخيوط

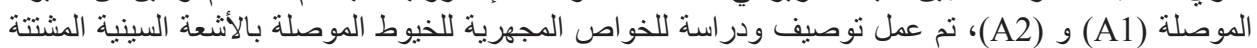

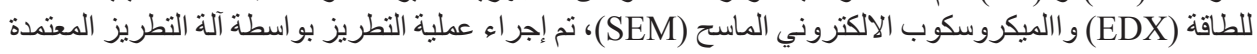

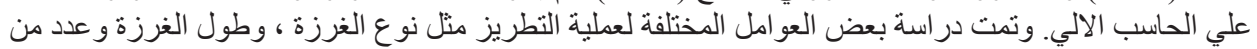

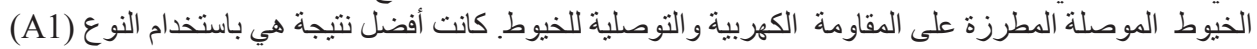

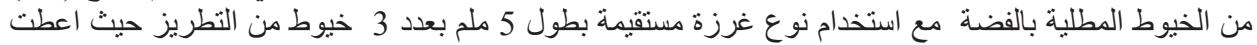

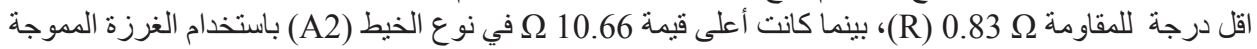

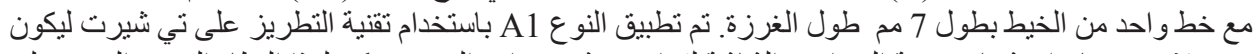

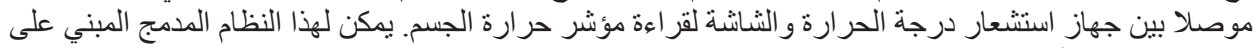
الخيوط الموصلة أن يجد تطبيقات جيدة في المجالات المختلفة مثل المجالات الطئل الطبية و وغير ها.
\end{abstract}

